\title{
David Oliver: The risks of discharging patients early against doctors' judgment
}

\author{
David Oliver consultant in geriatrics and general medicine
}

Berkshire

On 13 January the BBC reported the contents of an internal email to doctors from the medical director and chief nursing officer at the Royal Cornwall Hospital. ${ }^{1}$ In response to "significant pressure," and to free up bed capacity, the email urged doctors to discharge patients "earlier than some clinicians would like."

Last month the Guardian had carried a similar story from Norfolk and Norwich University Hospital, reporting internal memos urging senior doctors to find the "least unsafe option" in identifying patients to discharge. ${ }^{2}$

No doubt, senior operational and clinician managers at those trusts face an almost impossible balancing act. I'm sure that you'd find similar emails in dozens of acute hospitals around the NHS, given that they start each day in negative bed equity, with patients queuing in the emergency department, sometimes on trolleys in corridors.

What struck me about both cases was that the reported communications were explicit about the risk of harm. The email from Royal Cornwall Hospital went on to say that some patients would be at risk of harm but that this would be a "proportionate risk." You don't often get senior NHS managers being so candid about this lived reality: to that extent, I commend them. But we're entering dangerous territory when the professional clinical judgment of medics who have assessed and spoken to patients and their families, and who are personally accountable for decisions and consequences, is over-ridden, or when they're heavily pressured to act outside their comfort zone.

We all face daily balancing acts between the needs of individual patients and those of all patients and the wider system. We all accept managed risks in discharging patients. And we must maintain patient flow through beds, to improve our processes and minimise internal delays. That's a given. These stories suggest that we're now on far rougher ground.

The profession has been shaken by rare but high profile cases of gross negligence manslaughter, such as that against Hadiza Bawa-Garba. ${ }^{3}$ Through fear for our own livelihoods and reputations, our strong professional sense of a duty of care to patients is challenged and threatened by systemic and bed pressures.

But what's our position when we receive such instructions and pressure? The General Medical Council (GMC) has already issued guidance on formally escalating and documenting concerns whenever staffing, workload, or system failures may put patients at risk of harm. ${ }^{4}$ Guidance in the GMC's Duties of a Doctor ${ }^{5}$ suggests that doctors must prioritise their primary duty of care and patient safety-but also use resources efficiently and make balanced judgments. Colin Melville, GMC medical director, told me, "We always consider a concern raised with [us] on the specific facts of the case, taking into account the factors relevant to the environment in which the doctor is working." I don't find any of this especially reassuring, and nor do I see a defence of, "the medical director made me do it."

Another concern is what information patients should be given. Surely, they'll have to be told that they're being discharged earlier than their doctor might like, and we should document any safety netting we put in place for ongoing support and to reduce the risk of avoidable harm.

I'd like to see every patient and family given a letter co-signed by the chief executive, medical director, and chief nurse, making it clear that bed pressures meant that they were four square behind clinicians' necessary decisions to free beds and offering conversations with those who are concerned or may make formal complaints. When complaints or inquests or court cases arise those senior managers should visibly and unequivocally back the decisions of shop floor clinicians. Emails such as those in the news stories should occur only in the context of a formal, signed-off incident plan and not ad hoc.

In acute hospital medicine we accept risk, along with competing priorities, daily. But, increasingly, we can't reconcile our professional values, clinical autonomy, and duty of patient care with our fidelity to employers and the fear of courts, regulators, and harm to our own mental wellbeing.

Ultimately, acute hospital staff should not be backed into a corner or somehow labelled as a problem when the root cause is a failure to create sufficient capacity in community health 
and care services and decisions to cut the acute hospital bed base too far.

Competing interests: See bmj.com/about-bmj/freelance-contributors.

Provenance and peer review: Commissioned; not externally peer reviewed.

Cornwall early-discharge patients may "come to harm." BBC News 2020 Jan 13. https:// www.bbc.co.uk/news/uk-england-cornwall-51091947.

2 Campbell D, Duncan P. Doctors told to use "least unsafe" option in Norwich hospital.

Guardian 2019 Dec 20. https://www.theguardian.com/society/2019/dec/20/doctors-toldto-use-least-unsafe-option-in-norwich-hospital.
3 Vaughan J. Medical manslaughter: will the findings of an independent review be a tipping point for change? BMJ Opinion 2019 Jun 6. https://blogs.bmj.com/bmj/2019/06/06/medicalmanslaughter-will-the-findings-of-an-independent-review-be-a-tipping-point-for-change/.

4 General Medical Council. Raising and acting on concerns about patient safety. 12 Mar 2012. https://www.gmc-uk.org/ethical-guidance/ethical-guidance-for-doctors/raising-andacting-on-concerns.

5 General Medical Council. The duties of a doctor registered with the General Medical Council. https://www.gmc-uk.org/ethical-guidance/ethical-guidance-for-doctors/goodmedical-practice/duties-of-a-doctor.

Published by the BMJ Publishing Group Limited. For permission to use (where not already granted under a licence) please go to http://group.bmj.com/group/rights-licensing/ permissions 